DOI: $10.17805 /$ trudy.2019.1.7

\title{
МЕЖДИСЦИПЛИНАРНАЯ ПРОБЛЕМАТИКА РАБОТ И. В. РЕБЕЛЬСКОГО В ГОДЫ ВЕЛИКОЙ ОТЕЧЕСТВЕННОЙ ВОЙНЫ
}

\author{
И. Н. Елисеева
}

Московский гуманитарный университет

Аннотация: Рассмотрена деятельность И. В. Ребельского в период Великой Отечественной войны, выявлены идеи, которые можно отнести к области современной клинической психологии, экстремальной психологии, военной психологии и психологии научного творчества.

По материалам научного доклада на конференции «Кросс-культурные и междисциплинарные исследования в истории психологии: результаты и перспективы» (Москва, 24-25 ноября 2018 г.), проведенной в рамках проекта № 18-513-18017, поддержанного РФФИ.

Ключевые слова: И. В. Ребельский; история российской психологии; клиническая психология; экстремальная психология; психология научного творчества; военная психология; ятрогении; Великая Отечественная война

\section{INTERDISCIPLINARY ISSUES OF THE WORKS BY I. V. REBELSKY DURING THE GREAT PATRIOTIC WAR}

I. N. Eliseeva

Moscow University for the Humanities

Abstract: The paper considers the work of I. V. Rebelsky during the Great Patriotic War; it reveals the ideas that can be attributed to the field of modern clinical psychology, extreme psychology, military psychology, and the psychology of scientific creativity.

The research is based on the materials of the scientific reportat the conference "Cross-Cultural and Interdisciplinary Studies into the History of Psychology: Results and Prospects" (Moscow, 24-25 November 2018), held within the project No. 18-513-18017 supported by RFBR.

Keywords: I. V. Rebelsky; history of Russian psychology; clinical psychology; extreme psychology; psychology of scientific creativity; military psychology; iatrogenesis, Great Patriotic War

\section{Введение}

Работы врача-психиатра И. В. Ребельского хорошо известны историкам педагогики и педагогической психологии. Наряду в медицинской практикой И. В. Ребельский активно занимался популяризацией технологий организации народного просвещения и самостоятельного обучения. Эта сторона его деятельности была обращена, прежде всего, к аудитории молодых людей, только начинавших трудный путь освоения профессионального образования и не имевших ранее сформированных навыков систематического умственного труда. В исторических обзорах, как правило, упоминается 
Научные труды Московского гуманитарного университета 2019 № 1

его работа «Азбука умственного труда», которая выдержала не менее 14 изданий в 1920-1930-х гг.

Печатные работы И. В. Ребельского периода Великой Отечественной войны («Состояние психиатрической помощи на Западном фронте ко второй годовщине Отечественной войны и ее очередные задачи», «О поведении врача и сестры в операционной (к вопросу о ятрогении на войне)», «0 способностях и качествах научного работника») известны психологам в гораздо меньшей степени. Возможно, это связано с тем, что тематически работы связаны с деятельностью И. В. Ребельского в качестве главного психиатра фронта, а междисциплинарная проблематика этих текстов ранее не анализировалась.

В этой связи необходимо отметить, несколько исходных положений, опираясь на которые автор выделил междисциплинарное, связанное с развитием психологических идей, содержание работ И. В. Ребельского.

Первое. Ряд научных подходов и идей, практических технологий, которые впоследствии были развиты в рамках позднее оформившихся психологических направлений и отраслей, в период Великой Отечественной войны рассматривались в русле смежных с психологией наук, в том числе - в медицине и педагогике.

Второе. При выявлении междисциплинарной проблематики автор опирался на современные представления о дисциплинарном строении психологической науки и практики и проблемном поле отдельных психологических отраслей и направлений.

Третье. Рассмотрение социокультурного контекста и внутринаучных факторов, оказавших влияние на деятельность и содержание трудов ученого, является необходимым для историко-психологического исследования (Кольцова, 2008: 60; Олейник, 2008: 30).

Объектом исследования выступили работы 1944-1945 гг. психиатра И. В. Ребельского, официальные документы, отражающие оценку его деятельности в годы Великой Отечественной войны, воспоминания о деятельности и личности И. В. Ребельского, а также фрагменты его дневниковых записей.

\section{Работы И. В. Ребельского периода Великой Отечественной войны}

Обращаясь к статье И. В. Ребельского «Состояние психиатрической помощи на Западном фронте ко второй годовщине Отечественной войны и ее очередные задачи» (Ребельский, 1944), необходимо кратко рассмотреть основные подходы к организации психиатрической помощи военнослужащим в годы Великой Отечественной войны.

Основной задачей деятельности медицинской службы Красной Армии на 
протяжении всей войны было как можно более быстрое возращение в строй как можно большего количества раненных и заболевших военнослужащих. Наряду с врачами других специальностей эту задачу выполняли и военные психиатры (Коханов, Пак, 2016: 133). Опираясь на принципы, имеющие истоки в работе российских военных психиатров в годы Русско-Японской войны, и опираясь на опыт профилактики и лечения психических заболеваний в советский период, была развернута активная работа по построению системы оказания психиатрической помощи военнослужащим (там же: 134).

Анализ опыта работы первых двух лет войны позволил военным психиатрам подтвердить ряд положений, сформулированных в виде гипотез ранее, а именно:

1. В военное время не появляются специфические военному времени формы психических заболеваний и пограничных с ними состояний, однако изменяется патопластическая картина психозов (Ребельский, 1944: 37);

2. Степень тяжести психических заболеваний и пограничных с ними расстройств военнослужащих может существенно различаться: от незначительных отклонений в психической сфере (легкая раздражительность, переутомление, бессонница и т. д.) до психозов, и может определяться комплексом факторов, включая характер военных действий (Тимофеев, 1943: 29);

3. Одним из принципов организации психиатрической помощи военнослужащим является ее максимальное приближение к передовому району (Тимофеев, 1943: 33: Ребельский, 1944: 28);

4. Эффективная деятельность психиатров без взаимодействия с врачами других специальностей невозможна, поэтому психиатрия не может существовать изолированно от других отраслей медицины (Ребельский, 1944: 29);

5. Практика военной психиатрии не может быть ограничена сферой больничной работы, важным направлением деятельности психиатров становится психопрофилактика, включающая медицинские, психологические и социальные аспекты (Коханов, Пак, 2016: 135);

6. Немедикаметозная психотерапия (в основном гипносуггестивная терапия и трудовая терапия (Слабинский, 2015: 20)), как специальный метод лечения военнослужащих может быть эффективен при комплексном и систематическом использовании (Ребельский, 1944: 37).

Указанные положения былиприняты большинством психиатров, а в 1944 г., когда была опубликован доклад И. В. Ребельского, система оказания психиатрической помощи военнослужащим в Красной Армии уже функционировала.

Полагаем, что ни автор доклада, ни его коллеги не предполагали, что в дальнейшем, при обсуждении вопросов оказания сначала психолого-психиатрической (Александровский и др., 1991), а затем экстренной психологической помощи пострадавшим в чрезвычайных ситуациях эти положения, 
Научные труды Московского гуманитарного университета

2019 № 1

адаптированные к условиям времени, выступили основой для организации практической деятельности психологов (Учебное пособие ..., 2017: 36).

Так, в полной мере сохранили свою актуальность положения об отсутствии особых форм психических реакций и расстройств в чрезвычайных условиях, а также о зависимости степени тяжести состояния пострадавших от комплекса факторов, характеризующих как состояние их здоровья, индивидные, индивидуально-психологические особенности и пр., так и особенности чрезвычайной ситуации (там же: 11). Одним из основных принципов организации экстренной психологической помощи является ее максимальная приближенность по времени и месту чрезвычайных событий.

Психологи, оказывая экстренную психологическую помощь, работают в тесном взаимодействии с врачами, в том числе - врачами-психиатрами, а также сотрудничают с другими специалистами, включенными в оказание комплексной помощи пострадавшим.

Бесспорно, в деятельности психологов психологическая профилактика отдаленных психологических последствий чрезвычайных ситуаций играет важную роль, хотя ее содержание существенно отличается от психопрофилактической работы, проводимой военными психиатрами в годы Великой Отечественной войны. Что же касается применения технологий немедицинской психотерапии, то они включены в арсенал методов экстренной психологической помощи, хотя возможности их использования зависят от конкретных условий.

Анализируя состояние психиатрической помощи и определяя перспективы ее совершенствования на первой конференции психиатров Западного фронта в 1943 г., главный психиатр фронта подполковник медицинской службы И. В. Ребельский, в числе прочих задач указал на необходимость повышения квалификации старшего и среднего медицинского персонала (Ребельский, 1944: 35). На Западном фронте усилиями главного психиатра внедрялась система непрерывного образования медицинских кадров, которая охватывала не только медицинский персонал психиатрического профиля, но и распространялась (по вопросам, связанным с психиатрией) на медиков других специальностей. Формами мероприятий по повышению квалификации выступали систематические сборы специалистов, их научно-исследовательская работа, регулярные конференции. Например, «Утренние конференции врачей с короткими научными сообщениями самих врачей; открытые разборы больных специалистом-консультантом в присутствии всего врачебного коллектива госпиталя; заседания ВВК госпиталей, на которых представленные больные не просто кратко и формально докладывались, а серьезно и всесторонне обсуждались, - это, так сказать, внутригоспитальные мероприятия по повышению квалификации врачей на повседневном материале самих госпиталей» (там же: 35-36). 
Необходимо отметить, что вопросы подготовки медицинского персонала рассматривались многими врачами. В том числе, уделялось значительное внимание вопросам влияния взаимодействия медицинских работников с больным на динамику его выздоровления, его психическое состояние (Елисеева, Шойгу, 2016: 444).

В 1945 г. к этой проблеме обратился и И. В. Ребельский, подчеркивая важность выстраивания особого «экологичного» отношения врача к пациенту, отмечая, что услышанные слова врача могут сыграть определяющую роль в изменении психического и физического состояния пациента: «...мы забыли предостерегающие указания великого Павлова о том, каким мощным раздражителем является человеческое слово. Мы забыли, что небрежно, легкомысленно брошенное слово может породить в сознании больного и беспокойство, и тревогу, и боязнь, и страх, и обиду, и гнев, а эти состояния рикошетом ведут к расстройству физиологических функций, к понижению тонуса тканей и, следовательно, к уменьшению сопротивляемости борющегося за жизнь организма» (Ребельский, 1945a: 9). Автор обосновывал необходимость «психологической подготовки» больного к операции и важность продуманной организации работы медицинского персонала с целью минимизации психотравматизации больного и снижения вероятности развития ятрогений.

Стоит отметить, что название самой брошюры «0 поведении врача и медсестры в операционной (к вопросу о ятрогениях на войне)» указывает, что в ней автор раскрывает, применительно к условиям военного времени, содержание 8 главы «Поведение врача как источник иатрогении» известной книги А. Р. Лурия (Лурия, 1977: 94). Структура брошюры состоит из двух частей, первая из которых посвящена яркому и ироничному описанию поведения хирурга и его ассистентки в операционной и переживания больного, ожидающего операцию и ставшего свидетелем диалога медиков. Вторая же часть раскрывает психологические механизмы негативного изменения состояния больного, в ней приведены описания клинических случаев ятрогений, предложены способы снижения или устранения психогенного воздействия факторов, сопутствующих лечению военнослужащих. В этой работе И. В. Ребельский предстал не только как внимательный практик, приводя подробные и тонкие описания клинических случаев, но и как талантливый писатель и педагог, выбрав весьма нетривиальную и запоминающуюся форму изложения материала. Вызывает восхищение, что даже в исключительно сложных условиях военного времени психиатры, и в их числе И. В. Ребельский, продолжали придерживаться одного из основных принципов работы - индивидуального подхода к больному, которое выражалось, в том числе, в особом внимании к взаимодействию с ним (Коханов, Пак, 2016: 141). 
Научные труды Московского гуманитарного университета 2019 № 1

Сохранившиеся фрагменты дневника И. В. Ребельского раскрывают его собственное, полностью совпадающее содержанием печатных работ, отношение к людям, вовлеченным в войну, например: «Думаю о людях гетто. Пока они были в состоянии глубокого напряжения и шла борьба за жизнь они не давали ни психических заболеваний, ни психотических вспышек, а вот сейчас приходят ко мне каждый со своими тяжкими воспоминаниями (Каунас, 27 января 1945 г.)» (Кузнецова, 2003: Электр. ресурс). Необходимо отметить, что исключительно внимательное и чуткое отношение к пациентам было свойственно доктору И. В. Ребельскому и в мирное время. По воспоминаниям Любови Кузнецовой, дочери Иосифа Вениаминовича, в довоенное время он «...работал в больнице, консультировал в поликлинике. По выходным столовая наша битком набивалась больными, в большинстве своем иногородними, ждавшими встречи с отцом. И он помогал ... Помогал не только как врач, но и как ходатай. Если требовалось, вступался за людей, ходил по инстанциям» (там же). То есть, И. В. Ребельский уделял внимание не только собственно медицинским аспектам заболевания, но и социальным, характер которых мог повлиять на динамику выздоровления пациента или длительность ремиссии.

Проблему ятрогений в настоящее время можно отнести к смежной области клинической психологии и медицины, а брошюра И. В. Ребельского может быть весьма полезна при подготовке медицинского персонала по курсу медицинской психологии.

Еще один важный аспект в деятельности главного психиатра фронта И. В. Ребельского, который также нашел отражение в докладе на первой конференции психиатров Западного фронта - научно-исследовательская работа (Ребельский, 1944: 36). Важно, что И. В. Ребельский способствовал реализации целостного подхода в деятельности психиатров фронта: начиная с выявления взаимосвязей явлений, через построение гипотез о причинно-следственных связях и их механизмах, проверку гипотез практикой к широкому внедрению нововведений в деятельность фронтовых врачей. Научно-исследовательскую работу он рассматривал как необходимый элемент системы непрерывного образования врачей и как средство повышения эффективности психиатрической помощи. За 16 месяцев в 1944-1945 гг. под руководством И. В. Ребельского было издано 8 сборников научных трудов врачей фронта, включающих 95 статей (Центральный архив Министерства обороны - ЦАМО. Ф. 33. ОП. 686196. Единица хранения 5621. № записи 27216154. Л. 152).

О том месте, которое занимала в системе взглядов И. В. Ребельского научно-исследовательская работа, свидетельствует публикация в 1945 г. его доклада «0 способностях и качествах научного работника», где описан 
комплекс личностных качеств, необходимых исследователю в области изучения человека (Ребельский, 1945b). Доклад был сделан на конференции врачей эвакогоспиталей 3-го Белорусского фронта и по своему содержанию и стилю изложения близок к работам И. В. Ребельского по организации самостоятельного обучения, а его объем в большей степени соответствует лекции. Довоенный опыт И. В. Ребельского в качестве популяризатора эффективных технологий самообучения был в полной мере использован при подготовке доклада, прочтение которого оставляет яркое впечатление.

В докладе подчеркнута важность практической направленности исследований, учитывающей задачи развития страны. Ключевым моментом доклада является требование автора, обращающегося к ученым будущего, о соблюдении этических норм при проведении исследований с участием человека. Вероятно, тема строгого соблюдения этики в таких исследованиях была вызвана обоснованными опасениями в связи со снижением ценности человеческой жизни и норм морали в военное время. Таким образом, в содержании этой работы И. В. Ребельского можно выделить идеи, связанные с психологией научного творчества. Тема будущего, прогнозирования психогенных последствий войны раскрывается и в дневниковых записях Иосифа Вениаминовича в 1945 году: «Сидим с Румянцевым, делимся мыслями о том, как люди будут себя вести после войны. Увеличится ли количество самоубийств? Не придется ли нам бороться за место в жизни? Профессор Гельман сегодня утром в ответ на вопрос: Не снизилась ли цена жизни? Как будут себя вести люди, убившие собственными руками сотни людей? - сказал: Кто был чист, тот после войны станет еще чище, душа его как бы выкупается в страданиях и станет еще величественнее. И наоборот, кто был грязным, тот станет еще грязнее... (Велау, сануправление, 8 апреля 1945 г.)» (Кузнецова, 2003: Электр. ресурс).

Изучение работ Иосифа Вениаминовича было бы неполным без обращения к некоторым фактам его биографии. Так, будучи гражданским специалистом, И. В. Ребельский добровольцем ушел на фронт в июне 1941 г. В должности главного психиатра сначала Западного, а затем 3-го Белорусского фронта он выступил организатором системы психиатрической помощи военнослужащим. Достигнутые под его руководством результаты, прежде всего по проценту возвращения военнослужащих в строй, были неоднократно отмечены командованием. Подполковник медицинской службы И. В. Ребельский был награжден высокими государственными наградами, в том числе орденом Красной Звезды в 1944 году (Центральный архив Министерства обороны - Ф. 33. Оп. 690155. Единица хранения 3860. № записи 32870664. Л. 305) и орденом Отечественной войны II степени - в 1945 г. (Центральный архив Министерства обороны - ЦАМО. Ф. 33. Оп. 686196. Единица хранения 5621. № записи 27216154. Л. 152). 
Научные труды Московского гуманитарного университета 2019 № 1

Необходимо упомянуть деятельность И. В. Ребельского по организации помощи еврейским детям на территории освобожденной Литвы в 1944 г., которая не нашла отражения в его научных работах, однако, имела огромное значение для адаптации людей к условиям мирной жизни. Более 400 детей, выживших во время оккупации, нашли приют в двух детских домах в Каунасе и Вильнюсе: «Долгих три года дети жили в немыслимых условиях: на чердаках и в подвалах, в погребах, сараях. Многие прятались от фашистов в лесах, на свалках, в пещерах и даже в канализационных трубах. Теперь они вышли из своих укрытий и бродили по городу в поисках пропитания и ночлега. На детей страшно было смотреть: больные, истощенные, грязные, завшивленные, они сторонились людей, боялись света и солнца. Когда их пытались подкормить, они, выхватывая из рук все, что им давали, сразу же убегали, причем бежали, как от преследователей: пригибаясь к земле, петляя и пугливо озираясь (Вильно, 6 ноября 1944)» (Кузнецова, 2003: Электр. ресурс). Физическое и психическое состояние детей требовало не только организации их быта и воспитания, но прежде всего - медицинской, в том числе психиатрической помощи: «Слушая об этих детях, подумал, что надо чаще бывать в моих подшефных детских домах, выбираться туда пораньше, когда дети еще не спят, и работать с ними, работать. Привлечь к этому делу лучших врачей (Каунас, 13 ноября 1944 г.)» (там же).

Опыт работы с беспризорниками И. В. Ребельский получил еще в начале 20-х годах XX века в Саратове. В воспоминаниях дочери И. В. Ребельского приведено описание этого времени: «... со слов мамы я знаю, что на первом месте у папы стояли детские дома. Он сам, случалось, подбирал на улице беспризорников, приводил к себе, мама их отмывала, кормила, и папа отводил их в детдом» (там же). Работа И. В. Ребельского в качестве организатора народного образования в Саратове, его незаурядные организаторские способности были отмечены наркомом просвещения РСФСР А. В. Луначарским в 1921 г.: «...Беспартийный т. Ребельский в высшей степени старательный человек, чрезвычайно преданный делу и рационально к нему относящийся» (Ленин и Луначарский, 1971: 486). Так же отмечалось, что саратовские детские учреждения «живут более интенсивной жизнью и пользуются более сносными условиями, чем в большинстве других ...городов» (там же).

В послевоенный период И. В. Ребельский, находясь в Москве, продолжал популяризаторскую работу, сохраняя внимательное и заинтересованное отношение к подрастающему поколению: «Однажды, на дверях библиотеки я увидел объявление с приглашением на лекцию И. В. Ребельского “0 выборе профессии”. Эту лекцию и этот день я никогда не забуду... Суть его лекции состояла в том, что важна не профессия, которую выбирает молодой человек, а серьезность выбора и отношение к делу. После лекции я подошел 
к полковнику и сказал, что читал его книги, что затрудняюсь определить, в какой институт поступать, так как не вижу учебного заведения, где готовили бы специалистов по умственному труду... Иосиф Вениаминович расспросил о моих «проблемах», и я получил задание, нечто вроде контрольной работы ... Трудное было задание, но я его выполнил, как умел. Так начались наши с ним встречи...» (Сандер, Этлис, 1991: 385).

Найденные нами свидетельства о жизни и работе Иосифа Вениаминовича характеризует его как человека альтруистической направленности, чуткого и чувствительного к неблагополучию других, нетерпимого к проявлению моральной распущенности и ориентированного на высокие нравственные ценности, обладающего высокой работоспособностью и незаурядными организаторскими способностями.

Выводы. В трех рассмотренных работах И. В. Ребельского периода Великой Отечественной войны, можно выделить проблематику, которая в настоящее время относится полностью или частично к области клинической и экстремальной психологии и психологии научного творчества, при этом научные взгляды Иосифа Вениаминовича находились в русле современного ему медицинского знания. Деятельность И. В. Ребельского, характеризовавшуюся широкими интересами, выходящими за пределы одной науки, верой в способность человека к творческому развитию, готовностью оказать помощь и поддержку нуждающимся, нельзя назвать уникальной. История советской психологии, педагогики и медицины в 20-е - 40-е годы XX века знает много имен ученых и практиков, чья деятельность может быть охарактеризована подобным образом. К сожалению, эти имена известны весьма неширокому кругу специалистов.

Примечательно, что знакомство автора с трудами И. В. Ребельского состоялось в процессе реализации научно-практического проекта «Отечественные психологи в годы Великой Отечественной войны 1941-1945 гг.» (Елисеева, Шойгу, 2016: 438). Полагаем, что изучение наследия И. В. Ребельского наряду с наследием других ученых и практиков может не только дополнить представления о развитии отечественной психологической мысли, но и позволит отдать дань уважения этим людям.

\section{СПИСОК ЛИТЕРАТУРЫ}

Александровский, Ю. А., Лобастов, О. С., Спивак, Л. И., Щукин, Б. П. (1991) Психогении в экстремальных условиях. М. : Медицина.

Елисеева, И. Н., Шойгу, Ю. С. (2016) Научно-практический проект «Опыт решения психологических задач в годы Великой Отечественной войны» как форма деятельности студенческого психологического добровольческого движения Центра экстренной психологической помощи МЧС России // 
История отечественной и мировой психологической мысли: судьбы ученых, динамика идей, содержание концепций. Материалы всероссийской конференции по истории психологии «VI Московские встречи», 30 июня 02 июля 2016 г. / отв. ред. А. Л. Журавлев, В. А. Кольцова, Ю. Н. Олейник. М. : Изд-во ИП РАН. С. 438-448.

Кольцова, В. А. (2008) История психологии : Проблемы методологии. М. : Изд-во ИП РАН.

Коханов, В. П., Пак, Е. Т. (2016) К вопросу о междисциплинарном подходе в деятельности психиатров в годы Великой Отечественной Войны // Опыт решения психологических задач в годы ВОВ (1941-1945 гг.) : сборник материалов научно-практической конференции. М. : ФКУ ЦЭПП МЧС России. С. 131-161.

Кузнецова, Л. (2003) Собираю разрозненные брёвнышки народа своего... [Электронный ресурс] // Вестник. № 18 (329). URL: http://www.vestnik. com/issues/2003/0903/koi/kuznetsova.html (дата обращения 09.05.2015).

Ленин и Луначарский (1971) Письма, доклады, документы. М. : Наука.

Лурия, А. Р. (1977) Внутренняя картина болезней и иатрогенные заболевания. 4-е изд. М. : Медицина.

Олейник, Ю. Н. (2008) Периодизация истории психологии: проблемы и перспективы // Методология и история психологии. Т. 3. Вып. 2. С. 25-32.

Ребельский, И. В. (1944) Состояние психиатрической помощи на Западном фронте ко второй годовщине Отечественной войны и ее очередные задачи // Военная медицина на Западном фронте в Великой Отечественной войне. № 8. С. 18-40.

Ребельский, И. В. (1945а) О поведении врача и сестры в операционной (к вопросу о ятрогении на войне). Сан. упр. 3-го Белорус. фронта. Вильнюс.

Ребельский, И. В. (1945b) О способностях и качествах научного работника : Сокр. стенограмма доклада, прочит. на конф-ции врачей эвакогоспиталей фронта. Сан. упр. 3-го Белорус. фронта. Каунас : Тип. «Спиндулис».

Сандлер, А. С., Этлис, М. М. (1991) Современники ГУЛАГа : Книга воспоминаний и размышлений. Магадан : Кн. изд-во.

Слабинский, В. Ю. (2015) Отечественная психотерапия во время Великой Отечественной войны (1941-1945 гг.) // Вестник психотерапии. № 55 (60). С. 7-23.

Тимофеев, Н. Н. (1943) Организация психиатрической помощи в полевой санитарной службе// Военно-санитарное дело. № 1. С. 25-34.

Учебное пособие по дисциплине «Экстремальная психология» для курсантов МЧС России (2017) / под общ. ред. Ю. С. Шойгу. М. : ФГБУ ВНИИ ГОЧС (ФЦ). Дата поступления: 15.01.2019 г. 
Елисеева Ирина Николаевна - кандидат психологических наук, научный сотрудник научно-практического центра Военной академии Генерального штаба Вооруженных Сил Российской Федерации, преподаватель кафедры общей психологии и истории психологии Московского гуманитарного университета; член Межрегиональной общественной организации «Общество психологов силовых структур». Адрес: 111395, Россия, Москва, ул. Юности, д. 5. Тел.: +7 (499) 374-67-20. Эл. адрес: eliseevain2018@mail.ru

Eliseeva Irina Nikolayevna, Candidate of Psychology, Research Fellow, Scientific and Practical Center, Military Academy of the General Staff of the Armed Forces of the Russian Federation; Lecturer, Department of General Psychology and History of Psychology, Moscow University for the Humanities, Member, Interregional Public Organization "Society of Psychologists of Law Enforcement Agencies”. Postal address: 5, Yunosti St., Moscow, Russian Federation, 111395. Tel.: +7 (499) 374-67-20. E-mail: eliseevain2018@mail.ru

\section{Для цитирования:}

Елисеева И. Н. Междисциплинарная проблематика работ И. В. Ребельского в годы Великой Отечественной войны [Электронный ресурс] // Научные труды Московского гуманитарного университета. 2019. № 1. URL: http://journals.mosgu.ru/trudy/article/ view/934 (дата обращения: дд.мм.гг.). DOI: 10.17805/trudy.2019.1.7 